\title{
Effect of Lactulose on Calcium and Magnesium Absorption: A Study Using Stable Isotopes in Adult Men
}

\author{
Nobuo SEKI ${ }^{1}$, Hirokazu HAMANO ${ }^{2}$, Yuriko IIYAMA ${ }^{1}$, Yuzo AsANO ${ }^{1}$, Sadayuki KoKUBO ${ }^{1}$, \\ Koji YAMAUCHI ${ }^{2}$, Yoshitaka TAMURA ${ }^{2}$, Kazuhiro UENISHI ${ }^{3}$ and Hideki KuDOU ${ }^{3}$ \\ ${ }^{1}$ Food Research \& Development Laboratory, and ${ }^{2}$ Nutritional Science Laboratory, Morinaga Milk Industry \\ Co., Ltd., Zama, Kanagawa 228-8583, Japan \\ ${ }^{3}$ Kagawa Nutrition University, Sakado, Saitama 350-0288, Japan
}

(Received March 29, 2006)

\begin{abstract}
Summary To evaluate the effect of lactulose on calcium (Ca) and magnesium $(\mathrm{Mg})$ absorption, we performed a clinical trial with a double-blind, randomized, crossover design in 24 healthy adult male volunteers. The absorptions of $\mathrm{Ca}$ and $\mathrm{Mg}$ were evaluated by a single-labeling method using stable isotopes. The test foods, containing lactulose at a dose of $0 \mathrm{~g}$ (placebo), $2 \mathrm{~g}$ (low-dose), or $4 \mathrm{~g}$ (high-dose) together with $300 \mathrm{mg}$ of Ca containing $20 \mathrm{mg}$ of ${ }^{44} \mathrm{Ca}$, and $150 \mathrm{mg}$ of $\mathrm{Mg}$ containing $28 \mathrm{mg}$ of ${ }^{25} \mathrm{Mg}$, were administered orally. Urine samples were collected for $8 \mathrm{~h}$ after the ingestion of the test food. The ratios of stable isotopes in urine $\left({ }^{44} \mathrm{Ca} /{ }^{40} \mathrm{Ca}\right.$ and ${ }^{25} \mathrm{Mg} /{ }^{24} \mathrm{Mg}$ ) were measured by ICP-MS (inductively coupled plasma-mass spectrometry). The urinary stable-isotopes ratios $\left({ }^{44} \mathrm{Ca} /{ }^{40} \mathrm{Ca}\right.$ and $\left.{ }^{25} \mathrm{Mg} /{ }^{24} \mathrm{Mg}\right)$ increased with lactulose dosage. Significant differences were observed in the Ca ratio between placebo and high-dose lactulose $(p<0.01)$, and in the Mg ratio between placebo and low-dose lactulose and between placebo and high-dose lactulose $(p<0.01)$. Lactulose ingestion did not change the levels of bone-resorption markers (type I collagen cross-linked $\mathrm{N}$-telopeptide and deoxypyridinoline) in urine. The test foods did not cause any side effects. This study demonstrates that lactulose enhances the absorptions of $\mathrm{Ca}$ and $\mathrm{Mg}$ in adult men.
\end{abstract}

Key Words lactulose, stable isotopes, calcium absorption, magnesium absorption

Calcium (Ca) and magnesium (Mg) are essential elements for normal physiological functioning in humans, and dietary reference intakes (DRIs) have been established in many countries (1). However, a recent nutrition survey has indicated that the DRIs are not always satisfied (1). It is important that the DRIs of these elements are achieved, either by consuming an adequate daily diet or by ingesting food materials that increase their absorption from foods. Ca supplements and Casupplemented food products that have been designed to increase Ca intake, such as Ca-enriched milk and food products with a high $\mathrm{Ca}$ absorption rate (like milk Ca and Ca citrate malate), are available commercially. Vitamin D, casein phosphopeptide, casein phospho-oligopeptide, and indigestible oligosaccharides are also known to increase Ca absorption.

$\mathrm{Mg}$ plays a major role in bone and mineral homeostasis (2) and is a required cofactor in over 300 enzyme systems (1). However, there have been fewer studies on $\mathrm{Mg}$ than on $\mathrm{Ca}$, and hence further studies into the nutritional importance of $\mathrm{Mg}$ and the enhancement of its absorption are needed.

Lactulose (4-O- $\beta$-D-galactopyranosyl-D-fructose), an indigestible oligosaccharide, is a disaccharide that was first synthesized in 1930 (3) and is present in heat-sterilized milk (4). The property of lactulose as a bifidus fac-

E-mail: n_seki@morinagamilk.co.jp tor was confirmed in 1957 by Petuely (5). Many subsequent studies have investigated the importance of lactulose in the growth of intestinal bacteria, and it has also played a pioneering role in the field of prebiotics (6). In clinical applications, lactulose is used widely as a therapeutic drug for hepatic encephalopathy, and as a laxative worldwide (6).

It has been reported that lactulose increases the absorptions of $\mathrm{Ca}$ and $\mathrm{Mg}$ in dogs (7) and rats (8), and increases the rupture strength of the femur in an ovariectomized rat model of osteoporosis (9). In a clinical trial using double labeling with stable isotopes, Van den Heuvel et al. (10) found that lactulose (at 5 and $10 \mathrm{~g}$ ) increased the Ca absorption in postmenopausal women. However, there have been no reported clinical trials on the promotion of $\mathrm{Mg}$ absorption by lactulose.

The present clinical trial evaluated the effects of lactulose on $\mathrm{Ca}$ and $\mathrm{Mg}$ absorption, using a doubleblind, randomized crossover design. The absorptions of $\mathrm{Ca}$ and $\mathrm{Mg}$ were evaluated on the basis of ratios of stable isotopes of the two elements in urine after the oral administration of test food containing these isotopes.

There are two methods for measuring mineral absorption using stable isotopes: (i) a double-labeling method in which the stable isotope is ingested orally and another stable isotope is injected intravenously and (ii) a single-labeling method in which the stable isotope alone is administered orally (11). The double-labeling 
Table 1. Ingredients and components of test foods. ${ }^{1}$

\begin{tabular}{|c|c|c|c|}
\hline Ingredient & Placebo & $\begin{array}{l}\text { Low-dose } \\
\text { lactulose }\end{array}$ & $\begin{array}{l}\text { High-dose } \\
\text { lactulose }\end{array}$ \\
\hline Lactulose crystals (g) & 0.0 & 2.0 & 4.0 \\
\hline Milk-based Ca (g) & 0.9 & 0.9 & 0.9 \\
\hline $\operatorname{MgO}(\mathrm{g})$ & 0.2 & 0.2 & 0.2 \\
\hline Anhydride glucose crystals (g) & 4.0 & 2.0 & 0.0 \\
\hline $\mathrm{CaCO}_{3}$ containing stable isotope ${ }^{44} \mathrm{Ca}(\mathrm{g})$ & 0.05 & 0.05 & 0.05 \\
\hline $\mathrm{MgO}$ containing stable isotope ${ }^{25} \mathrm{Mg}(\mathrm{g})$ & 0.05 & 0.05 & 0.05 \\
\hline $30 \%$ hydrochloric acid $(\mathrm{mL})$ & 2.0 & 2.0 & 2.0 \\
\hline Distilled water $(\mathrm{mL})$ & 73 & 73 & 73 \\
\hline \multicolumn{4}{|l|}{ Component } \\
\hline Protein $(\mathrm{g})$ & 0.1 & 0.1 & 0.1 \\
\hline Fat $(\mathrm{g})$ & 0.0 & 0.0 & 0.0 \\
\hline Carbohydrate (g) & 4.0 & 4.0 & 4.0 \\
\hline $\operatorname{Ash}(\mathrm{g})$ & 1.1 & 1.1 & 1.1 \\
\hline Water $(\mathrm{g})$ & 74 & 74 & 74 \\
\hline Energy $(\mathrm{kcal})^{2}$ & 16.3 & 12.3 & 8.3 \\
\hline $\mathrm{Ca}(\mathrm{mg})$ & 300 & 300 & 300 \\
\hline $\mathrm{Mg}(\mathrm{mg})$ & 150 & 150 & 150 \\
\hline
\end{tabular}

\footnotetext{
${ }^{1}$ Values are given per dose.

${ }^{2}$ Energy value of lactulose $=2 \mathrm{kcal} / \mathrm{g}$.
}

method measures the true absorption of orally ingested minerals, but it requires the subjects to be given an intravenous injection of a stable-isotope solution. In contrast, the single-labeling method cannot be used to evaluate the true absorption of minerals, only the absorption relative to that of a placebo; however, it requires no intravenous injection. Since the objective of the present trial was to evaluate the effect of lactulose on relative mineral absorption, we adopted the singlelabeling method.

\section{MATERIALS AND METHODS}

Subjects. The subjects were 24 healthy adult males aged 23-42 y (33.5 $\pm 5.5 \mathrm{y}$, mean \pm SD). Subjects with diseases considered to affect mineral absorption (i.e., diabetes, renal disorders, galactosemia, osteoporosis, and those requiring hormone treatments) and those for whom the ingestion of milk or lactulose would cause diarrhoea were excluded.

This trial was performed in accordance with the Helsinki Declaration (October 2000, Edinburgh revised version). The institutional review board of the Medical Ethics Committee of Kagawa Nutrition University approved this clinical trial. The trial protocol was explained to each subject, who then provided his written informed consent to participate in the study.

Stable isotopes. The stable isotopes ${ }^{44} \mathrm{Ca}$ (in the form of $\mathrm{CaCO}_{3}:{ }^{44} \mathrm{Ca}, 95.9 \%$ ) and ${ }^{25} \mathrm{Mg}$ (in the form of $\mathrm{MgO}$ : ${ }^{25} \mathrm{Mg}, 99.2 \%$ ) were purchased from Trace Science (Russia).

Test foods. Three types of test food with the following lactulose contents were prepared: $0 \mathrm{~g}$ (placebo), $2 \mathrm{~g}$ (low-dose), and $4 \mathrm{~g}$ (high-dose). The stable isotopes were dissolved in hydrochloric acid (ultrapure 30\%, Wako Pure Chemical Industries, Japan) and distributed in bottles, each containing $20 \mathrm{mg}$ of ${ }^{44} \mathrm{Ca}$ and $28 \mathrm{mg}$ of ${ }^{25} \mathrm{Mg}$. Lactulose crystals (containing more than 98\% lactulose; MLC-97, Morinaga Milk Industry, Japan), glucose anhydride, a milk-based Ca (containing about 30\% Ca, $1 \% \mathrm{Mg}, 14 \%$ phosphate, $7 \%$ protein, 5\% water; ALAMIN 998, NZMP, New Zealand), Mg oxide, and tentimes-diluted hydrochloric acid (ultrapure 30\%, Wako Pure Chemical Industries) (see Table 1) were added to the bottles and mixed. The bottles were then filled to $80 \mathrm{~mL}$ with distilled water. The prepared colorless and clear solutions were kept in a refrigerator overnight to allow the ratios of the stable isotopes to equilibrate. The abundance ratios of ${ }^{44} \mathrm{Ca}$ to ${ }^{40} \mathrm{Ca}$ and of ${ }^{25} \mathrm{Mg}$ to ${ }^{24} \mathrm{Mg}$ in the test foods were about 4.4 and 3.3 times the natural abundance respectively. The test foods contained $300 \mathrm{mg}$ of $\mathrm{Ca}$ and $150 \mathrm{mg}$ of $\mathrm{Mg}$.

Protocol. The trial was performed according to a previously described method (12), and was performed in three periods using a three-group, crossover design. The placebo, low-dose lactulose, and high-dose lactulose foods were ingested following a 2-wk washout interval, where this duration was prescribed based on a previous report (12). The order in which the test foods were ingested at each period and in each of the groups is shown in Fig. 1. The trial was performed at the Lifestyle-Related Diseases Research Center, Kagawa Nutrition University, Saitama, Japan. The subjects were randomly divided into three groups by the permutatedblocks method within strata according to the Ca concentration in their urine before the trial and their age. After random allocation, the $\mathrm{Mg}$ concentrations in their urine and weight were compared among the groups, which revealed no differences. This trial was performed in a double-blind manner; the allocation table was sealed and kept strictly confidential until all of the data 


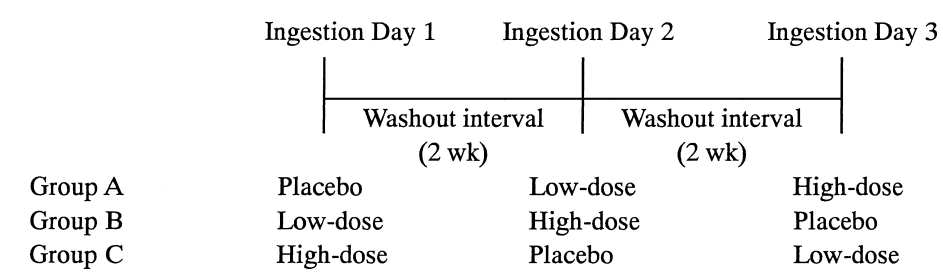

Fig. 1. Trial design. The trial was performed in three periods using a three-group, crossover design. The placebo (lactulose:

$0 \mathrm{~g}$ ), low-dose (lactulose: $2 \mathrm{~g}$ ), and high-dose (lactulose: $4 \mathrm{~g}$ ) foods were ingested following a 2-wk washout interval.

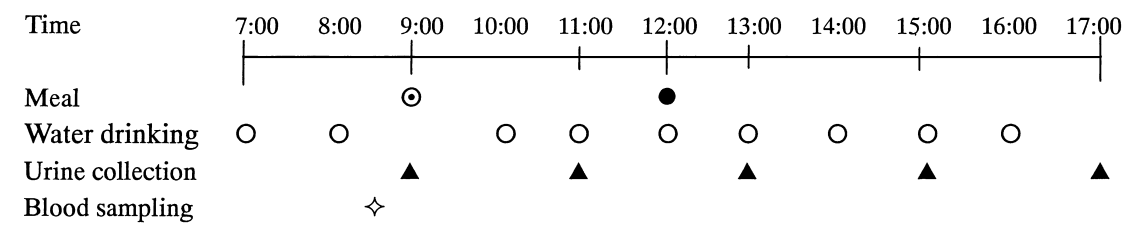

Fig. 2. Schedule of the ingestion day. After urination at 7:00 on the test day, the subjects drank $150 \mathrm{~mL}$ of mineral water every hour $(\bigcirc)$ until 16:00 (excluding 9:00). The subjects ate two toasted rice balls and the test food with $70 \mathrm{~mL}$ of mineral water at 9:00 $(\odot)$ and three toasted rice balls at 12:00 $(\bullet)$. All urine was collected every $2 \mathrm{~h}$ from 9:00 to 17:00 (i.e., five times; $\mathbf{\Delta}$ ). Blood was sampled (about $20 \mathrm{~mL}$ ) before the ingestion of the test food $(\diamond)$.

were finalized.

The subjects did not consume any foods containing indigestible oligosaccharides (e.g., lactulose, fructooligosaccharide, or difructose anhydrides III or IV) or supplements containing $\mathrm{Ca}, \mathrm{Mg}$, vitamin $\mathrm{D}$, or vitamin $\mathrm{K}$ from $1 \mathrm{wk}$ before the trial until after the completion of the trial. In addition, the subjects did not consume dairy products or foods containing bifidobacteria or lactic acid bacteria on the day before the trial.

The schedule of the ingestion day is shown in Fig. 2. The subjects ate Japanese wheat noodles (Ca, $20 \mathrm{mg}$; $\mathrm{Mg}, 17 \mathrm{mg}$ ) and a toasted rice ball (Ca, $3 \mathrm{mg}$; $\mathrm{Mg}$, $14 \mathrm{mg}$ ) at 19:00 on the day before the trial, and drank mineral water thereafter $(\mathrm{Ca}, 9.7 \mathrm{mg} / \mathrm{L} ; \mathrm{Mg}, 1.5 \mathrm{mg} / \mathrm{L})$. After urination at 7:00 on the trial day, the subjects drank $150 \mathrm{~mL}$ of mineral water every hour until 16:00 (excluding 9:00). The subjects ingested the test food and two toasted rice balls with $70 \mathrm{~mL}$ of mineral water at 9:00, and three toasted rice balls at 12:00. All urine was collected every $2 \mathrm{~h}$ from 9:00 to 17:00 (i.e., five times). Blood was sampled before the ingestion of the test food.

Stable-isotope analysis. The ratios of the stable isotopes $\left({ }^{44} \mathrm{Ca} /{ }^{40} \mathrm{Ca}\right.$ and $\left.{ }^{25} \mathrm{Mg} /{ }^{24} \mathrm{Mg}\right)$ were measured in the urine collected at 9:00 before the ingestion of the test food and in all of the urine collected between 11:00 and 17:00 (Combined-urine). The samples used for the measurement of stable isotopes were prepared as follows: $1 \mathrm{~mL}$ of ultrapure nitric acid $(70 \%$, Kanto Chemical, Japan) was added to $1 \mathrm{~mL}$ of Combined-urine in a Teflon test tube, which was heated at $120^{\circ} \mathrm{C}$ for $12 \mathrm{~h}$ and then its volume was increased to $10 \mathrm{~mL}$ with distilled water. The ratios of the stable isotopes were measured by inductively coupled plasma-mass spectrometry (HP4500, Yokokawa Analytical Systems, Japan) at Mitsui Chemical Analysis and Consulting Service (Japan).

Urinary mineral concentration. The $\mathrm{Ca}, \mathrm{Mg}$, and creatinine concentrations were measured in the Com- bined-urine and urine samples at each time point using the $o$-cresolphthalein complexone, xylidyl-blue methods and Jaffe's method, at SRL (Japan). The amounts of $\mathrm{Ca}$ and $\mathrm{Mg}$ in the Combined-urine are given as a product of the concentration of mineral and the weight of the urine.

Bone turnover index. Levels of type I collagen crosslinked $\mathrm{N}$-telopeptide (NTx) and deoxypyridinoline in the Combined-urine were measured by ELISA at SRL.

Blood analysis. The following hematological parameters were tested at SRL: GOT, GPT, $\gamma$-GTP, total cholesterol, HDL-cholesterol, triglyceride, white-blood-cell count, red-blood-cell count, platelet count, intact parathyroid hormone, osteocalcin, and 25-hydroxy vitamin D.

Adverse events were assessed by a doctor during the testing according to symptoms of the subjects.

Statistical analysis. Baseline characteristics: Twotailed ANOVA was used to compare the baseline characteristics of the subjects between the groups.

Urinary ratios of stable isotopes: A random-effect model (mixed model) analysis was used to assess the urinary ratios of the stable isotopes, in which the fixed effects were the treatment, the period, and the urinary ratio of stable isotopes before the test as covariates, and the random effect was the subjects. The degrees of freedom were adjusted using the Satterthwaite method, and the least-square means of the treatments were calculated. Dunnett's multiple comparisons were used to assess differences in the least-square means between placebo and high-dose lactulose and between placebo and low-dose lactulose. The analyses were two-tailed, and a probability of $p<0.05$ was considered indicative of statistical significance.

Urinary mineral contents: A random-effect model analysis was used to assess the urinary mineral contents, in which the fixed effects were the treatment and the period, and the random effect was the subjects. The 
Table 2. Baseline characteristics of the subjects. ${ }^{1}$

\begin{tabular}{lcccc}
\hline & Group A & Group B & Group C & Test result $^{2}$ \\
\hline Number of subjects & 8 & 8 & 8 & \\
Age $(\mathrm{y})$ & $33.1 \pm 5.0$ & $33.5 \pm 5.8$ & $33.8 \pm 6.2$ & $p=0.9760$ \\
Body weight $(\mathrm{kg})$ & $69.8 \pm 16.6$ & $65.6 \pm 6.6$ & $65.9 \pm 8.1$ & $p=0.7192$ \\
Urinary Ca/CRE ratio $($ both $\mathrm{mg} / \mathrm{mL})$ & $0.063 \pm 0.039$ & $0.061 \pm 0.060$ & $0.068 \pm 0.055$ & $p=0.9662$ \\
Urinary $\mathrm{Mg} / \mathrm{CRE}$ ratio $($ both $\mathrm{mg} / \mathrm{mL})$ & $0.041 \pm 0.012$ & $0.039 \pm 0.012$ & $0.041 \pm 0.016$ & $p=0.9220$ \\
25-OH vitamin D $(\mathrm{ng} / \mathrm{mL})$ & $25 \pm 3$ & $18 \pm 5$ & $21 \pm 2$ & $p=0.0032^{* *}$ \\
Intact parathyroid hormone $(\mathrm{pg} / \mathrm{mL})$ & $31 \pm 9$ & $37 \pm 12$ & $37 \pm 14$ & $p=0.4420$ \\
Osteocalcin $(\mathrm{ng} / \mathrm{mL})$ & $6.4 \pm 1.9$ & $7.3 \pm 2.0$ & $6.6 \pm 1.1$ & $p=0.5757$ \\
Blood Ca $(\mu \mathrm{g} / \mathrm{mL})$ & $95 \pm 5$ & $96 \pm 2$ & $96 \pm 5$ & $p=0.8370$ \\
Blood $\mathrm{Mg}(\mu \mathrm{g} / \mathrm{mL})$ & $24 \pm 1$ & $24 \pm 1$ & $24 \pm 1$ & $p=0.5141$ \\
Red blood cell counts $\left(\times 10^{4} / \mu \mathrm{L}\right)$ & $501 \pm 54$ & $519 \pm 19$ & $511 \pm 14$ & $p=0.5883$ \\
White blood cell counts $(/ \mu \mathrm{L})$ & $5,438 \pm 1,651$ & $4,900 \pm 731$ & $5,588 \pm 969$ & $p=0.4859$ \\
Platelet count $\left(\times 10^{4} / \mu \mathrm{L}\right)$ & $24.5 \pm 6.6$ & $20.8 \pm 3.0$ & $22.3 \pm 4.6$ & $p=0.3485$ \\
Total cholesterol $(\mu \mathrm{g} / \mathrm{mL})$ & $1,941 \pm 282$ & $1,863 \pm 229$ & $2,096 \pm 383$ & $p=0.3157$ \\
Triglyceride $(\mu \mathrm{g} / \mathrm{mL})$ & $1,453 \pm 1,753$ & $1,234 \pm 549$ & $1,473 \pm 875$ & $p=0.9037$ \\
HDL-cholesterol $(\mu \mathrm{g} / \mathrm{mL})$ & $595 \pm 181$ & $491 \pm 82$ & $546 \pm 109$ & $p=0.3042$ \\
GOT $\left(\mathrm{IU} / \mathrm{L} / 37^{\circ} \mathrm{C}\right)$ & $23.5 \pm 8.4$ & $20.6 \pm 5.2$ & $21.8 \pm 5.8$ & $p=0.6850$ \\
GPT $\left(\mathrm{IU} / \mathrm{L} / 37^{\circ} \mathrm{C}\right)$ & $24.8 \pm 21.0$ & $18.6 \pm 6.4$ & $26.5 \pm 14.4$ & $p=0.5603$ \\
$\gamma-$-GTP $\left(\mathrm{IU} / \mathrm{L} / 37^{\circ} \mathrm{C}\right)$ & $30.3 \pm 11.4$ & $23.0 \pm 6.6$ & $58.1 \pm 86.5$ & $p=0.3584$ \\
Bone mineral density $\left(\mathrm{g} / \mathrm{cm}^{2}\right)$ & $1.2 \pm 0.1$ & $1.2 \pm 0.0$ & $1.2 \pm 0.0$ & $p=0.3724$ \\
\hline
\end{tabular}

\footnotetext{
${ }^{1}$ Values are means \pm SDs.

${ }^{2}$ One-way ANOVA.

${ }^{3}$ Dual-energy X-ray absorptiometry method.

${ }^{* *} p<0.01$, comparison among the allocated groups.

CRE, creatinine.
}

Table 3. Effects of lactulose on mineral indices in the Combined-urine., ${ }^{1,2}$

\begin{tabular}{lrrr}
\hline & Placebo & Low-dose lactulose & High-dose lactulose \\
\hline Ca (mg) & $68.2 \pm 5.3$ & $71.7 \pm 5.3$ & $75.5 \pm 5.3^{*}$ \\
Mg (mg) & $39.9 \pm 1.7$ & $41.4 \pm 1.7$ & $41.6 \pm 1.7$ \\
NTx (nmol BCE/mmol CRE) & $22.33 \pm 1.3$ & $22.5 \pm 1.3$ & $24.4 \pm 1.3$ \\
Deoxypyridinoline (nmol/mmol CRE) & $3.0 \pm 0.1$ & $3.1 \pm 0.1$ & $3.0 \pm 0.1$ \\
\hline
\end{tabular}

${ }^{1}$ Combined-urine (all of the urine collected for $8 \mathrm{~h}$ after the ingestion of the test food).

${ }^{2}$ Values are least-square means \pm SEs.

${ }^{*} p<0.05$, difference from placebo.

$\mathrm{BCE}$, bone collagen equivalents. $\mathrm{CRE}$, creatinine.

Table 4. Changes in $\mathrm{Ca} /$ creatinine ratio in urine over time. ${ }^{1}$

\begin{tabular}{cccc}
\hline Hours after ingestion of test food & Placebo & Low-dose lactulose & High-dose lactulose \\
\hline 0 & $0.0717 \pm 0.0374$ & $0.0738 \pm 0.0382$ & $0.0785 \pm 0.0432^{*}$ \\
2 & $0.1348 \pm 0.0794$ & $0.1365 \pm 0.0657$ & $0.1494 \pm 0.0715$ \\
4 & $0.1774 \pm 0.0892$ & $0.1840 \pm 0.0752$ & $0.1856 \pm 0.0872$ \\
6 & $0.1380 \pm 0.0458$ & $0.1492 \pm 0.0539$ & $0.1510 \pm 0.0569^{* *}$ \\
8 & $0.0553 \pm 0.0377$ & $0.0571 \pm 0.0281$ & $0.0616 \pm 0.0282$ \\
\hline
\end{tabular}

\footnotetext{
${ }^{1}$ Values are means \pm SDs.

Differences from placebo: ${ }^{*} p<0.05 ;{ }^{* *} p<0.01$.
}

degrees of freedom were adjusted using the Satterthwaite method, and the least-square means of the treatments were calculated. Dunnett's multiple comparisons were used to assess differences in the least-square means between placebo and high-dose lactulose and between placebo and low-dose lactulose. The analyses were two-tailed, and a probability of $p<0.05$ was considered indicative of statistical significance.

The ratios of $\mathrm{Ca}$ and $\mathrm{Mg}$ to creatinine in the urine at each time point were compared between the groups 
Table 5. Changes in $\mathrm{Mg} /$ creatinine ratio in urine over time. $^{1}$

\begin{tabular}{cccc}
\hline Hours after ingestion of test food & Placebo & Low-dose lactulose & High-dose lactulose \\
\hline 0 & $0.0523 \pm 0.0147$ & $0.0528 \pm 0.0148$ & $0.0487 \pm 0.0153$ \\
2 & $0.0768 \pm 0.0228$ & $0.0770 \pm 0.0224$ & $0.0770 \pm 0.0249$ \\
4 & $0.0948 \pm 0.0234$ & $0.1009 \pm 0.0257$ & $0.0971 \pm 0.0296$ \\
6 & $0.0802 \pm 0.0208$ & $0.0858 \pm 0.0288$ & $0.0848 \pm 0.0300$ \\
8 & $0.0417 \pm 0.0139$ & $0.0452 \pm 0.0139$ & $0.0452 \pm 0.0162$ \\
\hline
\end{tabular}

${ }^{1}$ Values are means \pm SDs.

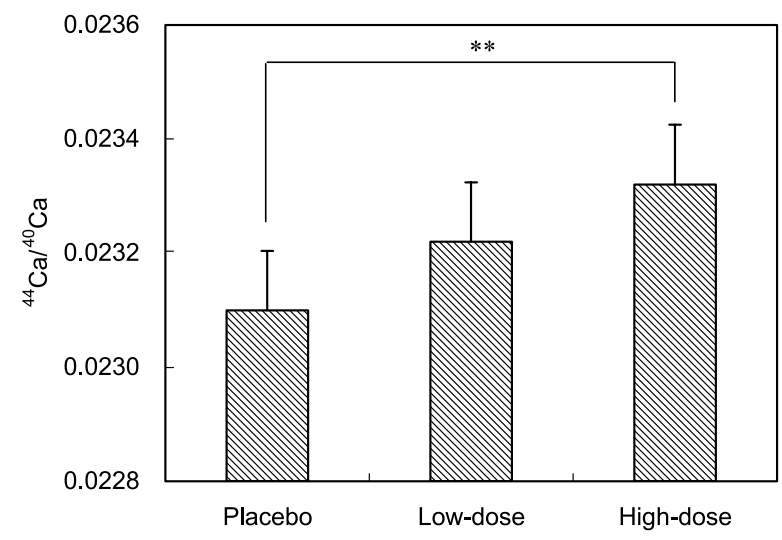

Fig. 3. Effect of lactulose on the ratio of Ca stable isotopes $\left({ }^{44} \mathrm{Ca} /{ }^{40} \mathrm{Ca}\right)$ in the Combined-urine (all of the urine collected for $8 \mathrm{~h}$ after the ingestion of the test food). The test food contained $0 \mathrm{~g}$ (placebo), $2 \mathrm{~g}$ (lowdose), or $4 \mathrm{~g}$ (high-dose) of lactulose together with $300 \mathrm{mg}$ of $\mathrm{Ca}\left({ }^{44} \mathrm{Ca}: 20 \mathrm{mg}\right)$ and $150 \mathrm{mg}$ of $\mathrm{Mg}\left({ }^{25} \mathrm{Mg}\right.$ : $28 \mathrm{mg}$ ). Values are least-square means \pm SEs. Placebo and low-dose lactulose, $n=24$; high-dose lactulose, $n=23$. ${ }^{* *} p<0.01$, different from placebo (Dunnett-Hsu test).

using the paired $t$ test.

All statistical analyses were performed using SAS software (version 8.02, SAS Institute, Cary, NC, USA).

\section{RESULTS}

\section{Subject characteristics.}

All 24 subjects completed the trial. One subject experienced food poisoning that was unrelated to the test food, and hence received an antibiotic $2 \mathrm{~d}$ before the second period; the data from this period (high-dose lactulose) for this subject were not used. There was no deviation from the protocol in any of the other subjects, and so all the other data were used. The subjects' baseline characteristics are listed in Table 2. The $p$ value was 0.15 or higher for all of the baseline characteristics except 25-OH vitamin D.

\section{Ratios of stable isotopes}

The least-square means of the urinary stable-isotopes ratios $\left({ }^{44} \mathrm{Ca} /{ }^{40} \mathrm{Ca}\right.$ and $\left.{ }^{25} \mathrm{Mg} /{ }^{24} \mathrm{Mg}\right)$ increased with increasing lactulose intake. Significant differences $(p<0.01)$ were observed in the Ca ratio between placebo and high-dose lactulose, and in the $\mathrm{Mg}$ ratio between placebo and low-dose lactulose and between placebo and high-dose lactulose (Figs. 3 and 4).

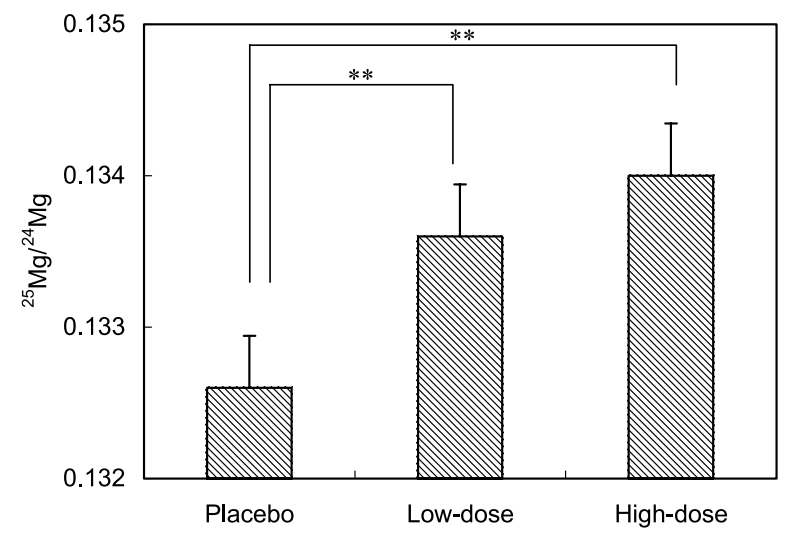

Fig. 4. Effect of lactulose on the ratio of $\mathrm{Mg}$ stable isotopes $\left({ }^{25} \mathrm{Mg} /{ }^{24} \mathrm{Mg}\right)$ in the Combined-urine. Values are least-square means \pm SEs. Placebo and low-dose lactulose, $n=24$; high-dose lactulose, $n=23$. ${ }^{* *} p<0.01$, different from placebo (Dunnett-Hsu test).

An analysis was performed incorporating baseline $25-\mathrm{OH}$ vitamin D values as a covariate, but this did not change the results.

\section{Urinary mineral excretion}

The least-square means of the amounts of $\mathrm{Ca}$ and $\mathrm{Mg}$ in the Combined-urine increased with lactulose dosage, and a significant difference was observed in the amount of $\mathrm{Ca}$ between placebo and high-dose lactulose $(p<0.05$, Table 3$)$.

The ratios of $\mathrm{Ca}$ and $\mathrm{Mg}$ to creatinine in the urine at each time point increased with lactulose dosage, and a significant difference was observed in the ratio of $\mathrm{Ca}$ to creatinine at $6 \mathrm{~h}$ between placebo and high-dose lactulose ( $p<0.01$; Tables 4 and 5$)$.

Bone turnover index

The least-square means of bone-resorption markers (NTx and deoxypyridinoline) were not associated with the lactulose intake, as indicated by an absence of significant differences among the test-food groups (Table $3)$.

Correlations between the amounts of minerals and ratios of stable isotopes in the Combined-urine

The amount of Ca was compared with the ratio of stable Ca isotopes $\left({ }^{44} \mathrm{Ca} /{ }^{40} \mathrm{Ca}\right)$, and the amount of $\mathrm{Mg}$ was compared with the ratio of stable $\mathrm{Mg}$ isotopes $\left({ }^{25} \mathrm{Mg} /{ }^{24} \mathrm{Mg}\right)$, in the Combined-urine (Fig. 5). The correlation coefficient between the urinary Ca excretion and the ratio of stable Ca isotopes was $0.633(p<0.001)$, and that of $\mathrm{Mg}$ was $0.457(p<0.001)$. 

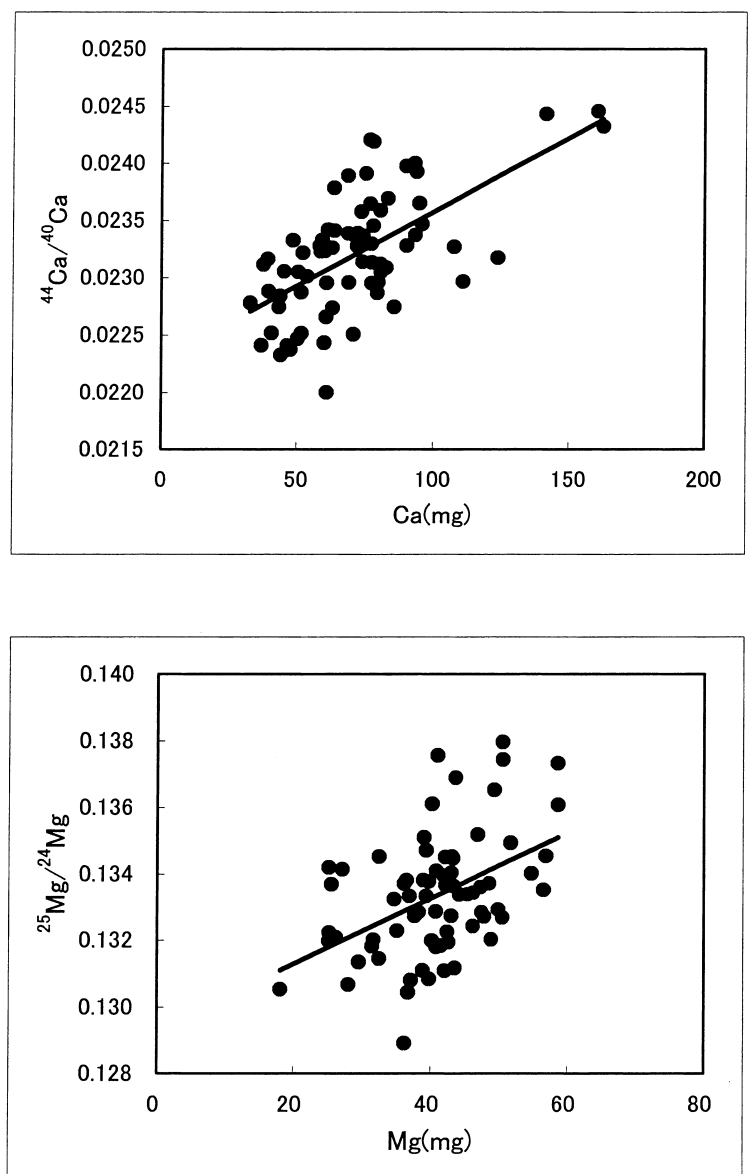

Fig. 5. Correlations between the ratios of stable isotopes in Combined-urine and the urinary mineral excretion after ingesting the test food $(n=71)$. Placebo and lowdose lactulose, $n=24$; high-dose lactulose, $n=23$. The correlation coefficients between the urinary excretions and the ratios of stable isotopes for $\mathrm{Ca}$ and $\mathrm{Mg}$ were $0.633(p<0.001)$ and $0.457(p<0.001)$, respectively.

\section{Safety evaluation}

The test foods caused no side effects.

\section{DISCUSSION}

In this clinical trial, we adopted the single-labeling method to evaluate the effects of lactulose on mineral absorption. The absorptions of $\mathrm{Ca}$ and $\mathrm{Mg}$ were evaluated on the basis of ratios of the stable isotopes in urine after the oral administration of test foods containing stable isotopes of $\mathrm{Ca}$ and $\mathrm{Mg}$. In the present study, the subjects were administered test foods in which the ratios of ${ }^{44} \mathrm{Ca}$ and ${ }^{25} \mathrm{Mg}$ were about four and three times higher than their natural abundance, respectively. A high ${ }^{44} \mathrm{Ca}$ or ${ }^{25} \mathrm{Mg}$ ratio in the urine after digestion of the test food indicates that the absorption of the mineral was also relatively high. Unlike the double-labeling method, the single-labeling method cannot be used to measure the true absorption, but it has been shown to exhibit a high correlation with the double-labeling method $(13,14)$, and its accuracy can be improved if the body size is included in the regression equation (15, 16); however, this method has needed ingestion of radioactive tracer. With the parallel design, it is impossible to measure the absorption of Ca or Mg using a single isotope method without adjusting by body size. With the crossover design, however, the influence of body size can be cancelled out. Therefore, a measurement of the relative absorption of Ca can be achieved using the single-labeling method with a crossover design, as has been described previously (12).

Correlations between the absorptions of $\mathrm{Ca}$ and $\mathrm{Mg}$ and their amounts in urine have been reported previously $(17,18)$, and many clinical trials have evaluated the absorptions of $\mathrm{Ca}$ and $\mathrm{Mg}$ based on urinary excretion $(19,20)$. In the present study, the amounts of minerals were compared with the ratios of stable isotopes in the Combined urine (Fig. 5). The presence of positive correlations between these variables suggests that the urinary excretions of $\mathrm{Ca}$ and $\mathrm{Mg}$ reflect $\mathrm{Ca}$ and $\mathrm{Mg}$ absorption, as reported previously $(17,18)$.

In the present clinical trial, to evaluate the absorptions of $\mathrm{Ca}$ and $\mathrm{Mg}$ from the ingested test foods, urine samples collected 2, 4, 6, and $8 \mathrm{~h}$ after the ingestion of the test food were combined and compared between the placebo group and the lactulose foods groups. Since the $\mathrm{Ca} /$ creatinine and $\mathrm{Mg} /$ creatinine ratios in urine had almost returned to the preingestion levels by $8 \mathrm{~h}$ after the ingestion of the test food (Tables 4 and 5), measurement of the ratios of the stable isotopes in the Combined-urine should have accurately reflected the absorptions of $\mathrm{Ca}$ and $\mathrm{Mg}$.

The ratio of stable $\mathrm{Mg}$ isotopes $\left({ }^{25} \mathrm{Mg} /{ }^{24} \mathrm{Mg}\right)$ in urine before the ingestion of the test food increased as the clinical trial progressed. To avoid bias due to the baseline values differing between the three study periods, the ratio of the stable isotope before ingestion of the test food was added as a covariate factor to the analysis model.

No abnormal baseline values of the physiological indices related to $\mathrm{Ca}$ and $\mathrm{Mg}$ metabolism (25-OH vitamin D, intact parathyroid hormone, osteocalcin, blood $\mathrm{Ca}$, blood $\mathrm{Mg}$, or bone mineral density) were detected in any of the subjects (Table 2). 25-OH vitamin D was the only index that differed among the groups. To assess whether the intergroup difference in 25-OH vitamin D affected the results, analyses were performed with and without 25-OH vitamin D included as a covariate; this did not change the results. Furthermore, this clinical trial was performed using a crossover design, which inherently cancels out any intergroup differences.

Several possible mechanisms underlying the enhancement of indigestible-oligosaccharide-induced mineral absorption have been proposed. The evertedsac and Ussing-chamber techniques have shown that indigestible disaccharides (e.g., maltitol and difructose anhydride (DFA)) directly increase the intestinal permeability of $\mathrm{Ca}$ in the absence of fermentation (21-23). This increase depends on the types of indigestible saccharides used in the Ussing-chamber technique (22, 24). DFA also shows a direct effect on the Ca permeability in vivo when the luminal perfusion method is applied (25). These effects may be due to indigestible 
oligosaccharides activating the paracellular transport pathway through tight junctions. Intragastric administration of $\mathrm{CaCl}_{2}$ solution with maltitol reduces gastrointestinal Ca transit and increases luminal fluid content (26). These effects promote the solubility of Ca and enable a larger area of the small intestine to absorb Ca over a longer period. Whether lactulose has the same effects as DFA and maltitol is not known because there are no reports on the relevant mechanisms of lactulose.

The intestinal bacteria ferment indigestible oligosaccharides in the large intestine and thereby produce organic acids (e.g., short-chain fatty acids, lactic acid, and succinic acid). The acidification of the large intestine makes the $\mathrm{Ca}$ and $\mathrm{Mg}$ salts soluble (they are insoluble at neutral $\mathrm{pH}$ ), and the resulting increase in the ion concentrations of these minerals increases their absorption in the large intestine (8). It has been reported that acidification in the ileal lumen with lactulose intake increases the apparent $\mathrm{Ca}$ and $\mathrm{Mg}$ absorptions (8). It has also been reported, in an experiment using the Ussing-chamber technique, that short-chain fatty acids directly increase the Ca permeability of the intestinal mucosa (27). Fermentative degradation of indigestible oligosaccharides such as lactulose by intestinal bacteria produces hydrogen gas, which is absorbed in the intestine and excreted via expiration. It has been reported that when $10 \mathrm{~g}$ of lactulose is ingested orally as a single dose, hydrogen is excreted via expiration for $8 \mathrm{~h}$, reaching a peak at $3 \mathrm{~h}(23)$. In addition, the total acetate production rate and acetate concentration in plasma are significantly increased from 3 to $6 \mathrm{~h}$ after the intake of a single dose of lactulose (28). These results suggest that lactulose is catabolized and converted to organic acids by intestinal bacteria within several hours. In the present study, the $\mathrm{Ca} /$ creatinine and $\mathrm{Mg}$ /creatinine ratios were compared between lactulose consumption and placebo at each time point (Tables 4 and 5). The biggest difference was found in urine at $6 \mathrm{~h}$ after ingestion, at which time assimilation by intestinal bacteria may have progressed, but not in urine at $3 \mathrm{~h}$, at which time the lactulose concentration in the large intestine may have been the highest. This suggests that the enhancement of $\mathrm{Ca}$ and $\mathrm{Mg}$ absorptions by lactulose is due mainly to organic acids produced by the catabolization of lactulose in the large intestine.

The enhancement of mineral absorption by indigestible oligosaccharides may be attributable not to multiple mechanisms but rather to a single process. Furthermore, the relative contribution of each process to the increasing mineral absorption may depend on the type of indigestible oligosaccharide and intestinal bacterial flora in individual hosts.

In summary this clinical trial has confirmed, using stable isotopes in adult men, that lactulose enhances the absorptions of $\mathrm{Ca}$ and $\mathrm{Mg}$.

\section{REFERENCES}

1) Food and Nutrition Board, Institute of Medicine. 1997. Dietary Reference Intakes: For Calcium, Phosphorus, Magnesium, Vitamin D and Fluoride, p 71-145, 190-
249. National Academy Press, Washington, D.C.

2) Bowman BA, Russell RM. 2001. Present Knowledge in Nutrition, 8th ed, p 273-280, 292-301. ILSI Press, Washington, D.C.

3) Montgomery EM, Hudson CS. 1930. Relations between rotatory power and structure in the sugar group. XXVII. Synthesis of a new disaccharide ketose from lactose. $J$ Am Chem Soc 52: 2101-2106.

4) Andrews GR. 1984. Distinguishing pasteurized, UHT and sterilized milks by their lactulose content. J Soc Dairy Tech 37: 92-95.

5) Petuely F. 1957. Bifidusflora bei Flaschenkindern durch bifidogene Substanzen (Bifidusfaktor). Z Kinderheilkunde 79: 174-179 (in German).

6) Mizota T, Tamura Y, Tomita M, Okonogi S. 1987. Lactulose as a sugar with physiological significance. Bull IDF 212: 69-76.

7) Beynen AC, Kappert HJ, Yu S. 2001. Dietary lactulose decreases apparent nitrogen absorption and increases apparent calcium and magnesium absorption in healthy dogs. J Anim Physiol Anim Nutr (Berl) 85: 6772 .

8) Heijnen AM, Brink EJ, Lemmens AG, Beynen AC. 1993. Ileal $\mathrm{pH}$ and apparent absorption of magnesium in rats fed on diets containing either lactose or lactulose. $\mathrm{Br} J$ Nutr 70: 747-756.

9) Igarashi C, Ezawa I. 1991. Effects of whey calcium and lactulose on the strength of bone in ovariectomized osteoporosis model rats. Ouyouyakuri 42: 245-253 (in Japanese).

10) Van den Heuvel EG, Muijs T, Van Dokkum W, Schaafsma G. 1999. Lactulose stimulates calcium absorption in postmenopausal women. J Bone Miner Res 14: 12111216.

11) Abrams SA. 1999. Using stable isotopes to assess mineral absorption and utilization by children. Am J Clin Nutr 70: 955-964.

12) Uenishi K, Ohta A, Fukushima Y, Kagawa Y. 2002. Effect of a malt drink containing fructooligosaccharides on calcium absorption and safety of long-term administration. Jpn J Nutr Diet 60: 11-18 (in Japanese).

13) Marshall DH, Nordin BEC. 1981. A comparison of radioactive calcium absorption tests with net calcium absorption. Clin Sci (Lond) 61: 477-481.

14) Wishart JM, Horowitz M, Morris HA, Need AG, Russo A, Jones KL, Sun WM, Nordin BEC. 1995. Relationship between fractional calcium absorption and gastric emptying. Eur J Clin Invest 25: 123-127.

15) Heaney RP, Recker RR. 1985. Estimation of true calcium absorption. Ann Intern Med 103: 516-521.

16) Heaney RP, Dowell MS, Wolf RL. 2002. Estimation of true calcium absorption in men. Clin Chem 48: 786788.

17) Nordin BEC. 1990. Calcium in Human Biology. p 137139. Springer-Verlag, Berlin Heidelberg.

18) Nishimuta M, Kodama N, Morikuni E, Yoshioka YH, Takeyama H, Yamada H, Kitajima H, Suzuki K. 2004. Balances of calcium, magnesium and phosphorus in Japanese young adults. J Nutr Sci Vitaminol 50: 19-25.

19) Whiting SJ, Pluhator MM. 1992. Comparison of in vitro and in vivo tests for determination of availability of calcium from calcium carbonate tablets. J Am Coll Nutr 11 : 553-560.

20) Fujita T. 1996. Calcium bioavailability from heated oyster shell-seaweed calcium (active absorbable algae cal- 
cium) as assessed by calcium excretion. J Bone Miner Metab 14: 31-34.

21) Goda T, Takase S, Hosoya N. 1993. Maltitol increases of transepithelial transport of calcium in rat intestine. $J$ Nutr Sci Vitaminol 39: 589-595.

22) Kishi K, Goda T, Takase S. 1996. Maltitol increases transepithelial diffusional transfer of calcium in rat ileum. Life Sci 59: 1133-1140.

23) Tamura A, Shiomi T, Shigematsu N, Tomita F, Hara H. 2003. Evidence suggesting that difructose anhydride III is an indigestible and low fermentable sugar during the early stages after ingestion in humans. J Nutr Sci Vitaminol 49: 422-427.

24) Mineo H, Hara H, Kikuchi H, Sakurai H, Tomita F. 2001. Various indigestible saccharides enhance net calcium transport from the epithelium of the small and large intestine of rats in vitro. J Nutr 131: 3243-3246.

25) Hara H, Kondo K. 2005. Difructose anhydrides III and IV equally promote calcium absorption from the luminally perfused rat small intestine. Biosci Biotechnol Biochem 69: 839-841.

26) Fukahori M, Sakurai H, Akatsu S, Negishi M, Sato H, Goda T, Takase S. 1998. Enhanced absorption of calcium after oral administration of maltitol in the rat intestine. J Pharm Pharmacol 50: 1227-1232.

27) Mineo H, Hara H, Tomita F. 2001. Short-chain fatty acids enhance diffusional Ca transport in the epithelium of the rat cecum and colon. Life Sci 69: 517-526.

28) Ferchaud-Roucher V, Pouteau E, Piloquet H, Zair Y, Krempf M. 2005. Colonic fermentation from lactulose inhibits lipolysis in overweight subjects. Am J Physiol Endocrinol Metab 289: E716-E720. 